\title{
Perspective
}

\section{The historical reference in restoration ecology: Re-defining a cornerstone concept}

\author{
Luis Balaguer ${ }^{\mathrm{a}, 1}$, Adrián Escudero ${ }^{\mathrm{b}, *}$, José F. Martín-Duque ${ }^{\mathrm{c}}$, Ignacio Mola ${ }^{\mathrm{d}}$, James Aronson ${ }^{\mathrm{e}, \mathrm{f}}$ \\ ${ }^{a}$ Department of Plant Biology I, Complutense University, Madrid 28040, Spain \\ ${ }^{\mathrm{b}}$ Department of Biology and Geology, Rey Juan Carlos University, Móstoles 28933, Spain \\ ${ }^{\circ}$ Department of Geodynamics, Complutense University of Madrid and Institute of Geosciences, IGEO (CSIC, UCM), Madrid 28040, Spain ${ }^{\mathrm{d}}$ \\ Research, Development and Innovation (R\&D) Service, Obrascón Huarte Lain, S.A. (OHL), Madrid 28046, Spain \\ ${ }^{\mathrm{e}}$ Centre d'Ecologie Fonctionnelle et Evolutive (CNRS-U.M.R. 5175), Montpellier 34293, France \\ ${ }^{\mathrm{f}}$ Missouri Botanical Garden, St Louis, MO 63110, USA
}

A B S T R A C T

Ecological restoration aims to revitalize ecosystem integrity and functionality following severe damage or degradation. Often, however, efforts are hampered by an incomplete or flawed concept of historical 'reference' used when choosing or constructing a target ecosystem or landscape to restore 'to'. This problem may stem from a culturally-skewed interpretation of history or from misunderstanding or underestimation of the role that humans have played in a given ecosystem's historical development and dynamics. While strongly confirming the importance of the reference concept in restoration ecology, we argue for the need to refine it, and to broaden the ways it can be conceived, developed, and applied. Firstly, the historical reference system informing a given restoration project should be grounded in both latent and active 'ecological memories', encoded and stored across relevant geographical and temporal scales. Further, the generally neglected geomorphic component of referencebuilding should also be addressed, as well as the contributions of human cultures to current ecosystem and landscape condition. Thirdly, ecosystems are historically contingent and multi-layered. Pre- versus post-disturbance compar-isons are insufficient. Instead, restoration scenarios should be seen as tapestries of multiple and succes-sive states. In sum, a well-conceived reference model helps promote and ensure the recovery and subsequent maintenance of historical continuity, i.e., the reestablishment of an impaired ecosystem to its historic ecological trajectory. We use case studies from Spain and Peru to illustrate how this approach can provide better goalposts and benchmarks, and therefore better guide the planning, implementation, and evaluation of effective restoration projects. 
1. Introduction

Twenty years ago, Wilson (1992: 340) famously wrote: The next

century will, I believe, be the era of restoration in ecology. Today, the science, politics, business, and practice - both professional and amateur - of ecological restoration are recognized as a global priority (CBD, 2012; Aronson and Alexander, 2013a, 2013b). Ecological restoration appears to be one of the most promising strategies for renewing ecosystem integrity and functionality in areas where degradation and transformation have gone too far, or gone awry (Young et al., 2005; Devoto et al., 2012). It also appears to be a galvanizing concept, and meeting place, for widely disparate interest groups and stakeholders looking for new models, new directions, new paradigms (Murcia and Aronson, 2014).

However, thirty years after the emergence of ecological restora-tion as a scientific discipline, and professional vocation, many people question whether restoration in general, and the selection of an historically-based reference system in particular, are relevant or practical in today's rapidly changing world (e.g., Hobbs et al., 2009). According to this line of reasoning, it is very often futile to try to restore past conditions; instead we should focus on promot-ing, managing, and molding 'novel' ecosystems (sensu Hobbs et al., 2006) to provide as much and as many desired ecosystem services as possible (Millar et al., 2007. Much has been written about this issue (e.g., Simberloff and Vitule, 2014), and we will not address it in detail here. Suffice it to say that we do not accept this argu-ment and that, despite substantial literature on the subject (see White and Walker, 1997; Egan and Howell, 2001; Clewell, 2009; inter alia), in the novelecosystem literature, and indeed generally in restoration ecology, conservation science, and related fields, much confusion persists with regards methodology, scope, and application of the reference concept. In our view, this remains the cornerstone concept, and conceptual tool that distinguishes ecological restoration from other related activities.

In this paper, we argue that the improvement in understanding, and use, of the concept of a reference model, can contribute signif-icantly to make ecological restoration more relevant, understand-able, and effective viable as a new paradigm, in social, economic, and cultural terms. In particular, we focus on the need to identify, select or construct locally-tailored historical references, using all the available and appropriate conceptual tools, so as to integrate both latent and on-going ecological and socio cultural processes and values. Among them, we will consider, especially, the geomor-phic and the human-cultural processes that are all too often neglected or mishandled when selecting or constructing a reference model. We consider the conceptual tools and the methodological techniques needed to select or construct the best possible historical reference. We recall that each and every biotic community is formed by species originating at different geological periods that co-occur transitorily as the outcome of sorting processes and histor-ical effects (Herrera, 1992). Their assembly, and, fortiori, their reas-sembly, is an historically contingent process (Fukami et al., 2005), contingent very often on human land use history, among other fac-tors (Balée, 2010). Attempts at reassembly should be approached not only with regard to theoretical community ecology and so-called assembly rules theory (Temperton et al., 2004), but also in the context of an historical sequence and ecosystem trajectory (Aronson et al., 1993), which also involves human land use changes, physical processes and landform dynamics (Collins et al., 2012).

Using recent case studies from Peru and Spain iwe attempt to illustrate the application of the historical reference concept, and to show how an expanded, operational reference not only provides goalposts and benchmarks, but also informs planning, implemen-tation, and evaluation of restoration projects that aspire to long-term effectiveness, success and broad-scale impact.

\section{The role of the past in the construction of the reference}

In ecology, as in human psychology (cf. Rathus, 2000), memory is the process by which the historical sequence of past events is encoded, stored, and retrieved. History, applied to ecosystems, remains encoded or imprinted, through its ecological consequences, in the assemblage and dynamics of the ecosystem mosaic, in what has been termed 'ecological memory' (Thompson et al., 2001). We argue that ecological memory should not be seen as a passive legacy. Rather, it is an active morphogenetic agent and indeed a primary dri-ver for current and future ecosystem configurations and functioning.

The 'strength' of ecological memories has been defined as the extent to which ecological structure and processes are shaped by their history (Peterson, 2002). Although this strength has been attributed only to biotic drivers, and the effects of past disturbance, ecological memory is also stored in landforms and in topographic heterogeneity, which are shaped by geomorphic and hydrological processes (Larkin et al., 2006). Additionally, social and cultural memory nurture ecological memory to the extent that human activ-ity interacts with, and partly determines, repositories and drivers of ecological memories, such as microclimate, landscape configuration, and soil structure and composition (Olsson et al., 2004). All these components are interwoven in ecological memory, not as a local collection of vestigial structures, but rather as a reservoir in continuous recombination and re-definition. In socio-economic terms- which are an essential correlate to the ecological sciences approach to res-toration -, the ecological memory is a inventory or inheritance under constant review. Finally, in philosophical and literary terms, it is a palimpsest written again and again though space and time, but at different rates, depending on the spatial scale considered.

At a regional scale, geographical, geological and climatic aspects of ecological memories have been configured over millions of years. Memories at the landscape scale include those encoded by past human activities over centuries, sometimes millennia. At the local scale, ecological memories, such as soil-borne seed banks, may take form in just a few years (Olano et al., 2011).

The relevance of this reservoir of memories, this palimpsest for ecological restoration practitioners to read, resides in its role as the historical component of ecosystem and landscape resilience (Bengtsson et al., 2003). This dual nature of ecological memory - as both a legacy of, and a driver for, ongoing and future ecosystem changes - has not been sufficiently explored by those thinking and writing about ecological restoration (but see Schaefer, 2009), or those actually doing it. For instance, the role of biological legacies (e.g., remnant living organisms, seed banks, and organic structures and biotic patterns, sensu Franklin et al., 1985), as well as of the persistent effects (cf. 'biological inertia' sensu Von Holle et al., 2003) are often underestimated or overlooked. This bias is reflected in both aquatic and terrestrial ecosystem restoration pro-jects whenever direct replacement, or reintroduction, of formerly present plant species by direct sowing or planting is undertaken as a knee-jerk reflex. In wetland ecosystem restoration, for exam-ple, evidence exists that revegetation is not the most effective approach available, either in ecological or economic terms (Moreno-Mateos et al., 2012). In tropical forest restoration, much evidence also suggests that assisted regeneration can occur from remaining tree cover, and seed or seedling banks (Harvey et al., 2008; Shoo and Catterall, 2013). As a third example, in heavily impacted sites slotted for re-greening, such as road or railway slopes, the widespread use of hydroseeding compares unfavorably with the spontaneous influx of wind-dispersed seeds from the sur-rounding landscape, provided remnant vegetation stands occur in 
proximity to the construction and revegetation site (Mola et al., 2011). These are just a few examples, among many others, of the oftenoverlooked contributions of the 'internal' and 'external' com-ponents of ecological memory (sensu Bengtsson et al., 2003).

We propose that ecological memory should be considered one of the conceptual pillars for constructing historically-based reference models. The challenge in ecosystem restoration is learning how to 'discover the past' (Egan and Howell, 2001), which means not only 'to set the system ticking again', as Don Falk (1990) so nicely put it, but also to acknowledge and take advantage of past legacies that shape or perhaps even dominate future ecosystem configurations. In this light, the first task of the restoration scientist and practi-tioner is to ascertain what seems to be, and what is not, a genuine expression of ecological memory. White and Walker (1997) identified the sources of information that can be used in the construction of a reference model for the restoration of an ecosystem that has been damaged, degraded or destroyed. They proposed a simple 4-cell matrix consisting of 'here and now', 'here and then' (i.e., in the past); 'there and now'; 'there and then'. Based on this idea, we suggest classifying the sources of ecological memories as:
a. Internal and active.
b. Internal and latent.
c. External and active.
d. External and latent.

The terms internal and external are used with respect to the dis-turbed ecosystem targeted for restoration. Links across ecological boundaries can be mobile, provided by organisms such as birds that move within and across landscapes (Lundberg and Moberg, 2003), visiting scattered remnant trees (Manning et al., 2009). Such links may also involve a wider social context through varying media, markets, social networks, collaborative organizations, or legal structures that create or mediate ecological links or barriers (Barthel et al., 2010). In turn, active memories are those that remain functional and operational. Every remnant organism, struc-ture or process of an ecosystem is the outcome of an ongoing his-torical process and, consequently, is an integral part of active memory. Finally, latent memories are those memories encoded by past events, but not currently expressed. They may emerge spontaneously, or be retrieved through human effort or interven-tion. Examples of latent ecological memories emerging through historical layers are particularly common in semi-cultural or socio-ecological ecosystems, where past human activities are intimately intertwined within the ecological background or bio-physical matrix.

A relevant case of latent memory was found during the search for the appropriate historical reference to guide the ecological res-toration of an unusual type of forest in coastal Peru, called 'lomas' which is a type of fog oasis occurring within the regional matrix of the Atacama-Peruvian Coastal Desert biome. In this highly frag-mented formation, high levels of diversity and endemism are threatened by present human activity (Balaguer et al., 2011). The aim was to construct an appropriate historical reference on the basis of scientifically-validated benchmarks such as genetic diver-gence, phenotypic specialization, and ecological performance. In this study, we found that the available data only made sense as inputs to develop the reference in the context of the local cultural background and, in particular, in the context of Inca agroforestry systems in the pre-Columbian historical period. It transpired that the most diverse fragments of fog oases in the Peruvian Coastal Desert, were not merely the outcome of past human practices but, what is more relevant, landscapes whose persistence ultimately rely on the feasibility of retrieving the latent memory of the socioecological systems that generated and maintained them. Consequently, their restoration today requires references that incorporate sustainable practices by modern people to emulate the outcomes of earlier, historical uses prior to European conquest.

Notably, the Peruvian lomas are not an isolated case in Latin America. Ancestral Maya, in Northern Central America, established a profound and complex relationship with tropical forests, giving rise to anthropogenic forests termed by Ford and Nigh (2009) as 'Maya Forest Gardens'. In contrast to coastal Peru, where massive cultural disruption thoroughly eradicated previous Inca practices, the pre-Columbian cultural engagement with the forest remains prominent in at least a few Mesoamerican management systems (Nigh and Diemont, 2013). Thus, crucial keys to the effective choice and construction of an historical reference model for the lomas in coastal Peru (Balaguer et al., 2011), are latent ecological memories whereas in the cases referred to in Mexico, Guatemala, and Belize, those memories are still active (Ford and Nigh, 2009). It should be obvious that the interface between ecological and cultural memories is a highly relevant and fertile area for reflection and development in the general context of ecosystem restoration.

Once a restoration team has identified the relevant sources of information, their next task is to select or construct one or more reference models with the help of all data concerning ecological

- and cultural - memories that can bring the notion of historical continuity to the heart of the restoration process (Clewell and Aronson, 2013a). The approach is to seek to reestablish - or emu-late, insofar as possible - the historical trajectory of ecosystems, before they were deflected by human activity, and to allow the restored system to continue responding to various environmental changes (Clewell and Aronson, 2013b). This is not a static vision, but rather a dynamic and adaptive one. Contrary to what is some-times said, contemporary restoration ecologists and practitioners do not aim to 'recreate' the past-something clearly impossible-but rather strive to reestablish the historical trajectory of an impaired ecosystem as it was developing before it was deflected by human disturbance, 'so that it may continue its evolution in response to future conditions' (Clewell and Aronson, 2013a). For this ambitious approach to succeed, it must contend with - and overcome - a widespread, but misleading concept of ecosystem development, either based on a simplistic binary interpretation of history, or on an outdated paradigm of human disturbance in ecological succession, as we will see in the next section.

\section{The two-phase interpretation of history and other blind alleys}

As sketched out above, the historical reference model idea is all too often understood as selecting a unique or quintessential land-mark or benchmark, corresponding to something left behind in an irretrievable past. It may be conceived of as an ideal or 'original, pre-disturbance' state or baseline (Hall, 2005), from a time before the ecological system at issue crossed one or more 'irreversible' ecological thresholds (Aronson et al., 1993). In refinement of this notion, however, some authors assert that there remain very few examples of true historical or 'original' ecosystems to be found any-where today (Hobbs et al., 2009), and even if there were, there is no way to truly restore something 'to' them. Consequently, these authors argue, most ecosystems can only be evaluated in terms of relative degree of divergence from some historical reference (Jackson and Hobbs, 2009). However, this concept of historical ecosystem all too often incorporates the strange idea that history somehow ends with the emergence of human influence. This pre-analytic vision is often deeply rooted in the cultural matrix of those areas that Alfred Crosby (2004) identified as neo-Europes (i.e., most of the temperate regions of the Americas, southern South Africa, Australia, and New Zealand), in which the homeland left behind by European settlers in the newly colonized lands far from Europe was consciously or unconsciously recreated as cultural landscapes. 
In this psycho-geo-historical context, the challenge that restoration practitioners set for themselves was often oriented towards the reconstitution of an authentically 'indigenous', pre-European state or condition, where 'Nature' had existed as a supposedly untouched wilderness, something pure, untainted and 'untrodden'. This two-phase recreation of history is not always justified (Clewell and Aronson, 2013a, among many others). For Europeans, the 'historical truth' of the landscapes where they work is rarely two phasic, but rather represent and sustain a cultural tapestry and palimpsest built of layer upon layer of human and pre-human history (Hall, 2005). Constructions of restoration references on the basis of two-phase interpretations of history are also particularly sensitive to the effects of the so-called 'shifting baseline syndrome', according to which each human generation accepts as a baseline assumption the ecosystem and landscape configurations that occurred at the beginning of their careers, or in their childhood, and therefore uses these as baselines to evaluate ongoing change (Pauly, 1995).

As an example, the fine-grained floodplains of meandering gravel-bedded streams characteristic of a large part of mid-Atlantic streams of the United States, have been widely accepted as the pre-European historical ecosystem, although adjusted to changing dis-charge and sediment loads after European settlement. The work of Walter and Merritts (2008), however, indicates that these flood-plains were actually fill terraces developed by aggradation, i.e. depo-sition of sediments, due to damming of thousands of mildams during the 17th-19th-centuries. In turn, the meandering channels incised on those floodplains are mostly a result of dam-breaching. Despite the fact that some other authors have expressed reservations about these findings (see for example Bain et al., 2008), the fact is that they provide an example of how what it was a general interpretation of a 'natural geomorphic reference' of floodplains formed by a combina-tion of migrating, meandering stream channels and overbank depo-sition of silts and clays, needs to be re-assessed, at least regionally, over broad areas of Mid-Atlantic streams in the United States. If the findings of Walter and Merritts (2008) are confirmed, this would validate the need for developing a new 'anthrophogenic geomorphic reference' to guide stream and river restoration in the eastern US and, possibly, for other relevant ecoregions as well.

In other cases, restoration actions are all too often undertaken on the basis of inadequately verified, historical reference models, based on outdated Clementsian concepts of deterministic succes-sion pathways. Ecological succession is often treated synony-mously with natural regeneration, and erroneously taken as spontaneous return to an 'original' state of some illdefined nature. This putative return to past ecosystems, ('ecosystem resurrection'), underlies the notion of 'passive restoration', which assumes that ecological succession does 'all that is necessary' (Bradshaw, 1996, p. 6) to achieve 'natural recovery' once the causes of environmental degradation have been removed. Secondary succession, fueled by innate resilience in the target ecosystem, may make it possible to 'restore' more forests than do native tree plantations or more com-plex, and 'active' forest restoration initiatives in temperate and Mediterranean ecosystems (Rey Benayas et al., 2008). However, counter-examples can be found where the alleged expansion of native forest, led both by global change drivers and management actions, seem to be pushing some habitats and endangered species in the Iberian Peninsula to the verge of extinction (Box 1). In fact, in large areas of Europe what is unquestionably taking place is the colonization of abandoned crop fields and deforested lands by a limited number of tree species (FAO, 2010); not all these coloniza-tion events constitute an expression of ecological memory, but rather only those that originate from assemblages of plants and animals that survive in remnant refugia (Lundberg and Moberg, 2003). Consequently, spontaneous tree colonization by native spe-cies does not represent proof of autogenic forest restoration. The question as to whether or not passive restoration can lead to multiple trajectories that could be acceptable in a restoration sce-nario, as one anonymous reviewer of this manuscript suggested, is an illustration of the complexity of the issues at hand.

Box 1. Biodiversity threatened by 'forest' expansion.

In Spain, woodland cover (i.e., tree cover) has increased by ca. $55 \%$ (6.5 million hectares) in the last three decades (Fig. 1). Environmental authorities, NGOs, protected area managers, and scholars have acknowledged this fact as an unexpected, and seemingly positive, consequence of various global changes particularly of land abandonment - or even as a genuinely positive, and intended outcome of the national biodiversity conservation policy (see for instance Ministerio de Medio Ambiente, 1999). However, very few of the threatened species of vascular plants in Spain occur in woodlands or forests in the mediterranean-climate eco-systems. The vast majority of those species occur in open areas, such as scrublands or grasslands. Paradoxically, pas-sive restoration, or even ecological restoration when taken as 'assisted succession', is actually threatening the future of Spanish populations of many endangered species in former open areas. These ecological restoration initiatives that may erode, rather than preserve, biodiversity do not lack an historical reference, quite the contrary, they are carried out in the name of a presumed historical forest that may have never existed or had only a limited range. The legend that original Spanish forests were so thick that a squirrel could travel across the Iberian Peninsula without ever touching the ground (Blanco et al., 2001), is a pervasive myth that has been told with exactly the same words for Russia (Tarsaidze, 1950), Wales (Ginzberg, 1942), and the Appala-chian mountains of the southeastern USA (Freinkel, 2007). The 'continuous forest myth' in the Mediterranean Basin is in clear contrast with the well documented role of megaher-bivores as keystone species capable of maintaining open grasslands (Owen-Smith, 1987). The abundance, in the Paleolithic era, of an array of megaherbivores including woolly mammoths, forest elephants, steppe bison, cave bears, rhinoceri, aurochs, and horses (Freeman, 1973; Haws, 2012) suggests that Mediterranean forests were interspersed with extensive grassy plains and shrublands. To some extent, human disturbances (burning, livestock grazing, ploughing, and mining) took over the role of main-taining this landscape heterogeneity in the Mediterranean basin after the human-driven extinction, or domestication, of those various megaherbivores. Blondel et al. (2010) have already argued that many traditional land-use practices may act as surrogates of previous natural disturbance regimes in the region. How human activity shifted in place and evolved over historical time goes a long way to explain present-day landscapes (Carrión et al., 2010).

Our goal is simply challenge the assumption that the appropri-ate historical reference in regions currently being colonized by shrub and tree species is in fact a forest. Conceivably, such a pre-mise may stem from a cultural bias that attributes to forests a superior status, over other ecosystem types. This is a tendency we would call 'forestphilia' (paraphrasing 'biophilia', the memora-ble term coined by Wilson in 1984).

Summing up this section, history is not - or not always - a two-phase system, but rather a sequential layering of episodes and periods in a dynamic ecological and evolutionary world. Similarly, the notion of a forest as a steady-state historical ecosystem is 
inspired by the static 'balance of nature' paradigm. This paradigm common to Occidental and Asiatic traditions alike, is obsolete from the perspective of modern ecology (Pickett and White, 1985; Wu, 2011). Thus, in restoration ecology, we must transcend rigid dichotomies such as historical versus 'novel', pristine versus humanized, or pre- versus post-disturbance ecosystems. The com-mon assumption that 'historical' invariably means 'pre-distur-bance', 'pre-alteration', or 'predegradation' (see for instance Miller et al., 2012) is as erroneous as assuming that there is only one ecologically legitimate or ideal reference system for every res-toration site and that we, as scientists or practitioners, only have to look for it. This notion leads to the argument referred to above that the historical reference concept is a 'pitfall' (e.g., Pickett and Parker, 1994) whereas in fact it should simply lead us to take up the task more thoughtfully, and holistically (see Aronson et al., 1995). This is obviously not a trivial task, especially when many cultural layers are superimposed and contribute to- or limit the scope of - the prevailing socio-ecological memory as is the case in most parts of the world. As we argue below, identifying a series of successive references state that can be used as benchmarks over time in the restoration process may be more effective than choosing a single reference model once and for all. Furthermore, both socio-eco-nomic desiderata, often understood in terms of ecosystem services, should be identified along with purely ecocentric ones.

\section{Multiple sequential historical references: a case study}

Given the complexity and difficulty of the restoration task in most contexts, the selection of a single historical reference may be inappropriate or impossible (Aronson and Van Andel, 2012). An alternative approach is to retrace the historical scenario of transformation leading the ecosystems and landscapes at issue to their pres-ent condition, and then, to develop a multiple sequential reference model in three steps (Aronson et al., 2012; Clewell and Aronson,
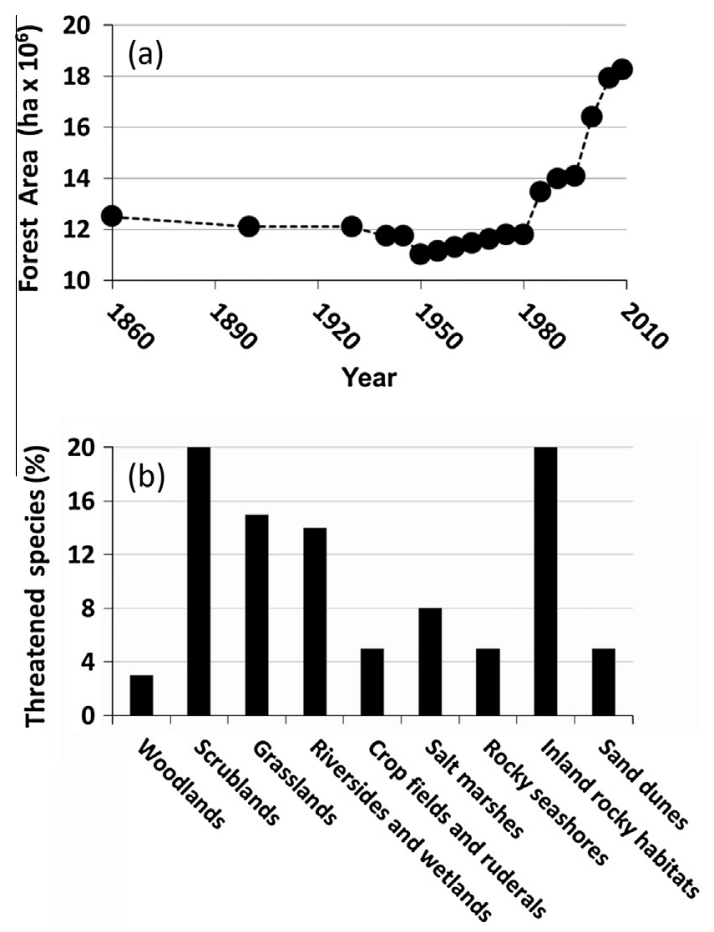

Fig. 1. Discrepancy between tree cover expansion and ecological preferences of endangered species of vascular plants in mediterraneanclimate ecosystems of Spain. (a) Changes in forest cover over the last ca. 150 years $(S E C F, 2011)$. (b) Distribution of threatened species of vascular plants $(n=315)$ among habitat types (based on Iriondo et al., 2009; Bañares et al., 2010). 2013a). We illustrate these steps with an ongoing project wherein an ecological restoration strategy is developed on the basis of a geomorphologically-informed historical reference for sand quarries in Eastern and Central Spain (see also Box 2). We also aim to illustrate how the most appropriate historical reference can sometimes be a human-shaped landscape selected from an historical sequence of land transformation that spans the last thousand years.

\section{Box 2. Historical references in geomorphic restoration.}

Ecological restoration projects often fail to incorporate the geomorphic component into the historical reference system. In post-mining landscapes, where this component is particularly important, the goal would entail seeking to blend the postrestoration hillslopes with the surrounding landforms shaped over millions of years - insofar as possi-ble (Hancock et al., 2003; Martín-Duque et al., 2010). We argue that, even in these scenarios, the ecological restora-tion approach may be guided by a reference selected from an historical series of shifting ecosystem configurations over the past centuries or millennia. In those regions, where the landscape has been modified by centuries of human activity, the post-mining restoration reference should inte-grate knowledge from both historical geomorphology and archaeology, that is, from the emerging discipline known as geoarchaeology (Butzer, 2008). This ecological restora-tion approach has been already adopted by some local mining companies to comply with regulations, to lower uncertainty and environmental risks, and to foster a positive corporate image. Here, we present an on-going restoration project in a sand quarry (El Machorro, Guadalajara, Spain) illustrating the application of such a 'geoarcheologicallyinformed' historical reference system. In this scenario, any historical restoration reference may seem unattainable, since we cannot restore the original, pre-mining hillslopes. Obviously, any attempt to reconstruct the consolidated bed-rock of these past landforms by using unconsolidated waste spoils would result in highly unstable slopes (Martín-Duque et al., 2010). The point, however, is that history generates a sequential stream of references, and, in this particular site, the landscape configuration from the Romanesque period (11th-12th century $\mathrm{CE}$ ), already shaped by human activity, may well aid to recall latent ecological processes. Thus, guided by this historical reference, the ecological restora-tion strategy was to trigger the erosive formation of gullies on a typical highwall-bench slope quarry topography (Fig. 2a). In consonance with the contour patterns of the existing gullies in the region, a specially blasting design was employed to trigger these erosive processes on the highwall in order to mimic those of the geomorphic histor-ical reference (Fig. 2b and c). Highwall current surface and expected evolution were modeled in three dimensions (Fig. 2d and e) to ensure that it becomes a hydrological transfer zone subjected to moderate erosion. Additionally, the lower bench was restored as an alluvial-colluvial piedmont, designed to trap sediment outflows within its channels. We expect that this geomorphic configuration will ultimately provide the stability required to enable spontaneous colonization of the site by propagules arriving from nearby patches of remnant vegetation (Fig. 2f), which usually becomes apparent over the first spring season after work completion (Martín-Duque and Balaguer, unpublished data). 
(a) First step: Identifying and selecting the relevant ecological

memories to reveal the successive 'states' through which local ecosystems and landscapes have developed. In our example, the geomorphic setting is a set of plateaux or 'mesas', and slopes or 'cuestas' shaped on Upper Cretaceous sediments. The mesas are topped by a caprock of limestone, while the cuestas are formed by clayey and gravelly sands. As shown in Fig. 3, in the 9th-10th century CE, these mesa and cuesta landforms were covered mainly by woodland. From the 11 th century CE onward, the limestone caprocks were used to build Romanesque churches, houses, and stone fences. Additionally, people excavated the cuestas, obtaining sand and clay for house-building. Both processes led to the formation of slope gullies (Lucía et al., 2011). In the last third of the 20th century, industrial development triggered the demand of quartz (silica) sand and kaolin, and the exploita-tion of sands readily available in these hillslope gullies led to the excavation of dozens of quarries scattered throughout the region.

\section{(b) Second step: Mapping out a possible and desirable restoration}

trajectory going forward into the future. Here, the processes of reinforcement, reconnecting, and recuperating lost biodi-versity, ecosystem functioning, and the delivery of multiple ecosystem services to multiple beneficiaries should be charted. The overall outcome sought is above all recuperation of historical continuity, values of many sorts, and resilience in the face of a rapidly changing environment (Clewell and Aronson, 2013a). In our case study from Spain, a greater and broader environmental awareness has led, over the last few decades, to the protection of some ecosystems and landscapes dotted with abandoned and active quarries, as well as to a legislative response to regulate mine site restoration in Spain. This in turn has led to more than two hundred legal amendments being adopted in the last 30 years (http://www.westlaw.es). In our case study area, although some quarries will continue to provide kaolin for several more dec-ades, mainly for export to a vigorous pottery industry in other regions of Spain, the abandoned quarries are no longer regarded as a resource, but rather as degraded 'badlands'. The presence of these kaolin mines at the very edge of protected areas has prompted a revision of past operational standards, and greater thoroughness in the writing up of ecological res-toration protocols and guidelines. Following the approach described in this paper, one of us (JFMD) has proposed and implemented the Romanesque period model (11th-12th centuries CE) as the historical reference for the ecological res-toration of these abandoned quarries (Box 2).

(c) Third step: Testing the model by presenting it to key stake-

holders, decision-makers, and concerned local people. This helps, first, to verify the historical processes depicted, sec-ond, to determine what really makes sense in terms of time-line and expectations going forward, and, finally, to identify alternative futures and to agree upon shared priorities, val-ues, and goals. In our case study, growing awareness of the identity and cultural values, as well as of the ecological and healthy features of traditional rural landscapes, has evolved dramatically over recent decades (Fig. 4). In Spain, natural park managers are mandated to regulate mining activities in the vicinity of the protected area, and in our case, the administration of the main protected area of this region, namely the Alto Tajo Natural Park (Guadalajara Prov-ince) determined that the proposed geomorphic model, based on the local historical reference, fulfills the current societal demand, and they subsequently approved the proposed restoration plan.
Multiple sequential reference models typically entail selecting two or more historical states as beacons for the successive stages in the restoration process (e.g., reference 1 for the first 5-15 years, reference 2 for the period 15-30 years, etc.) in the aim of finally assisting or guiding the target ecosystem back to the preferred state or trajectory. Alternatively, the model can be used to select a single long-term reference state from the various historical peri-ods identified. In this case, the multiple sequential references inform the overall selecting process and help us bear in mind the need for an holistic approach to restoration, combining, and responding, to ecological, socio-economic, and cultural drivers and desiderata (Aronson et al., 2012). In our case study from Spain, for example, we selected the Romanesque period in preference to earlier and later references, on the basis of the needs and values of people in the area today, and the demographic and economic trends predicted for the future (Box 2).

\section{Towards an operational historical reference: restoring to the}

future

The concept of historical reference is not explicitly present in the widely-cited definition of ecological restoration of the Society for Ecological Restoration, namely 'the process of assisting the recovery of an ecosystem that has been degraded, damaged, or destroyed' SER (2004). The term 'recovery', in the SER definition, implies retrieving a target ecosystem with historical meaning, and historical continuity, with respect to former trajectories (Clewell and Aronson, 2013a). Ecological restoration is, then, not only the act of assisting recovery, but also that of guiding ecosys-tem recovery according to a consciously selected model of an his-torically-based reference system. Thus, the restoration practitioner guides or steers the restoration process towards an historically-grounded configuration, selected over other potential alternatives. This distinguishes ecological restoration from ecosystem design and creation, both of which are components of ecological engineer-ing, and have their place in our future, but are not ecological restoration.

Probably, the greatest challenge in this selection process concerns the way we incorporate the legacies of past human activities (see McCune et al., 2013). Often, anthropogenic transformations are viewed as leading to damage and degradation. However, degra-dation may be 'in the eye of the beholder'. It is worth recalling in this context that in the same paper in which Arthur Tansley (1935) introduced the term 'ecosystem', he also openly criticized those ecologists who assumed that human activities are merely destructive, or play no part in successional processes. Those assumptions or intellectual positions, he argued, were only valid as a description of truly pre-historical ecosystems that existed prior to the emergence of Homo sapiens. With similar insight, Ze'ev Naveh (2000) stressed that - at least in the Holocene, human activ-ity has been an integral part of ecosystem regulatory processes. Going further, Waltner-Toews et al. (2003) have called for a para-digm shift with regards to ecosystem management: human society must learn to manage ecosystems not from the outside in, but rather from the inside out.

In relation to the magnitude of our impacts, and collective foot-print, humans are nowadays the primary agent modifying the Earth's surface (Hooke et al., 2012), even including the deep sea (Ramirez-Llodra et al., 2011; Van Dover et al., 2013; Barbier et al., 2014). Anthropogenic disturbance and transformation are nearly ubiquitous on emerged lands worldwide and apparently go back at least 3000 years for much of the inhabited portions of our planet (Ellis et al., 2013). Nearly seventy-five years ago, Clements and Sherford (1939) described the ecological conse- 

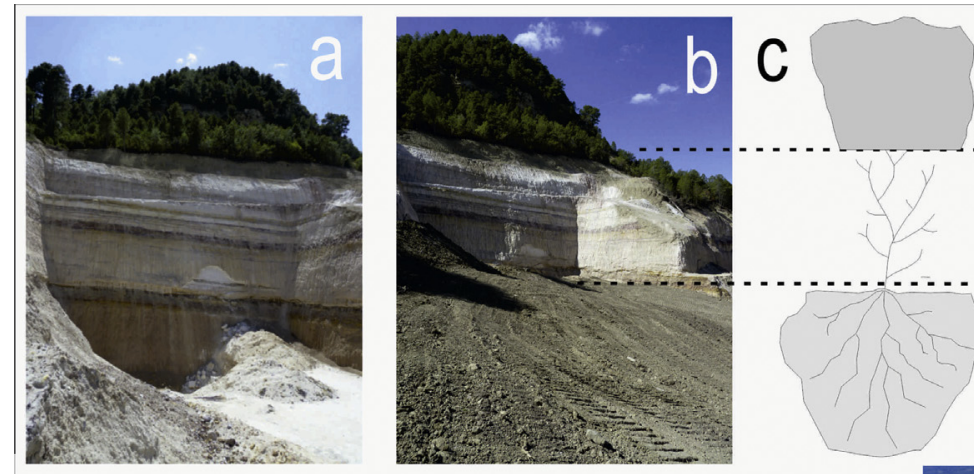

LIMESTONE CAPROCK

AT THE TOP OF MESA

Drainage area entering

the slope quarry

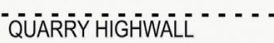

To be ecologically restored

based on a geomorphic

historical reference, to become

. a gullied transfer zone . . . . .

QUARRY BENCH

Already ecologically restored

mimicking an alluvial - colluvial

slope piedmont
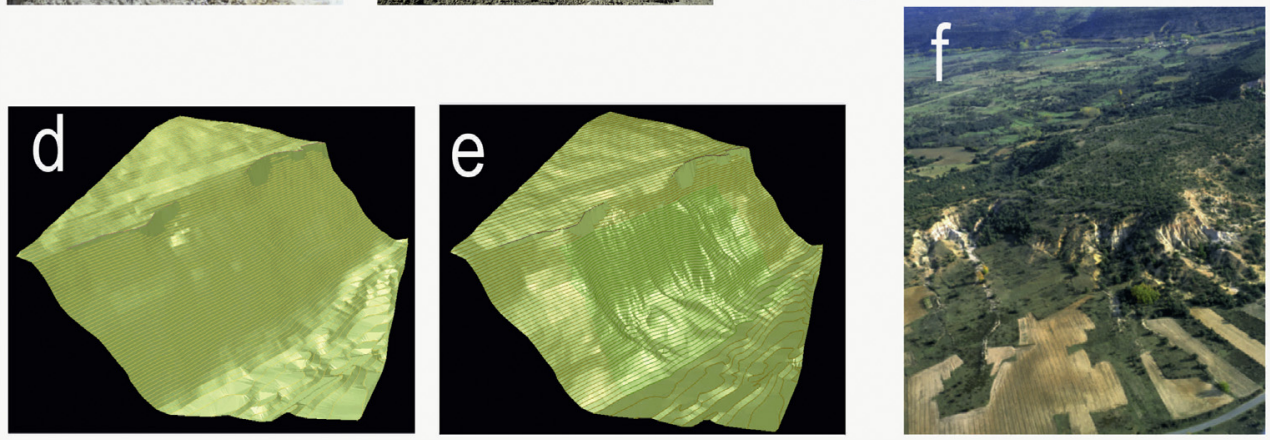

Fig. 2. Ecological restoration process of a sand quarry in Central Spain guided by an historical reference based on landforms from the 11th-12th century CE (see text for further details).

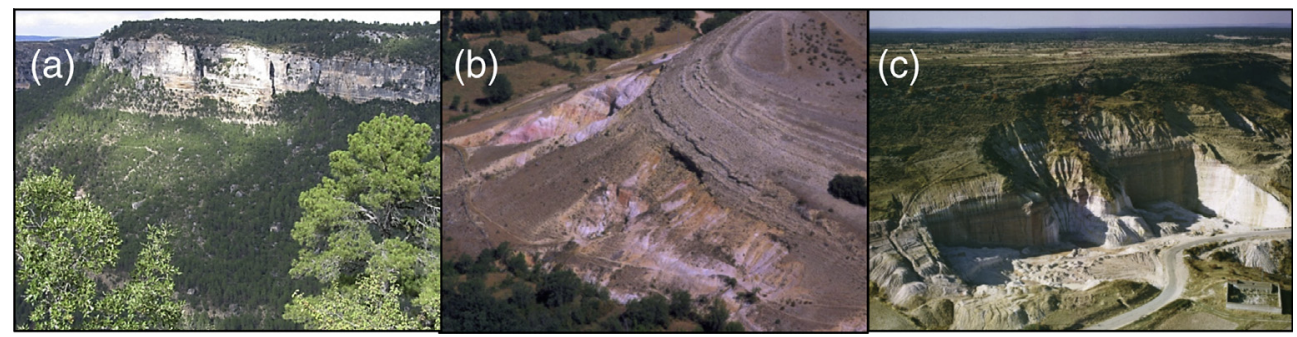

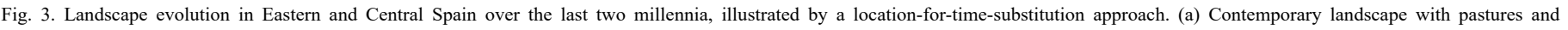

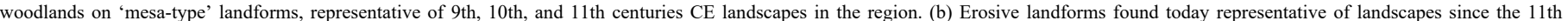

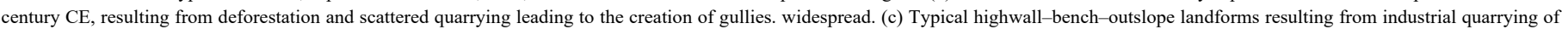

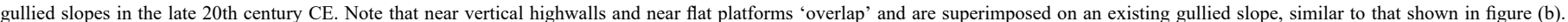

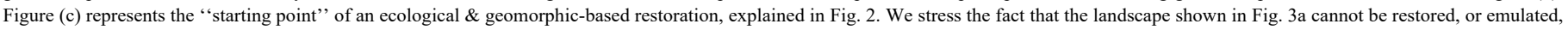

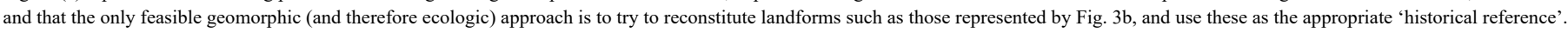

quences of human activity as giving rise to a 'new order'. Seventy years later, Hobbs et al. (2009) suggested that where we humans have-possibly irreversibly - brought upon ourselves, and the bio-sphere, a new ecological order, the historical reference as a tool and baseline in restoration and conservation is obsolete. This 'new ecological world order' vision of those authors, as well as their notion of 'novel ecosystems thinking', is to a certain extent a retelling and rewording of the 'pristine past' myth. To wit, the concept of a 'pristine ecosystem', unaltered by humans, is recast as the 'historic ecosystem', and the rationale presented is, roughly, that since we cannot go back to the pristine ecosystem, let us work to maximize the services provided by this new ecological world order we have 'created'. But, are we breaking free from the 'pris-tine' myth only to plunge into a 'new order' myth? In fact, far from a binary dichotomy- historic/pristine versus novel/humanized -, what actually exists 'out there', is a nearly continuous gradient of landscape human-modification (Wu, 2010). From relatively unspoilt ecosystems, barely influenced by human activity, such as certain areas of the Amazonian primary rain forests (Bush and Silman, 2007), to native ecosystems invaded by alien species with- out previous human disturbance (Mascaro et al., 2008), we move all the way across the spectrum to indisputably cultural land-scapes. Along this spectrum, the alleged irreversible thresholds or tipping points that separate and define ecosystem categories or stages are, in practice, hard to demonstrate (Woodworth, 2013).

In closing, we emphasize that the value in selecting, or con-structing, historically-based references for use in ecological resto-ration lies in seeking to ground our restorative actions, in the complexity and integrity of ecosystems and landscapes whose dynamics and integration derive from their on-going historical processes in larger landscape and bioregional matrices. Similar compelling arguments are appearing in regards conservation-ori-ented interventions as well (Bull et al., 2014) under the terms 'baseline specification' and 'reference frames'. In both cases, we argue the historically-based reference, or reference frame, remains a cornerstone concept. Reference-building draws on both the latent and the active ecological memories encoded in layers upon layers of pre-human and human history, including the geomorphic component. In sum, the historically-based reference is not a model to be copied, but rather a template and beacon to aid in the search 


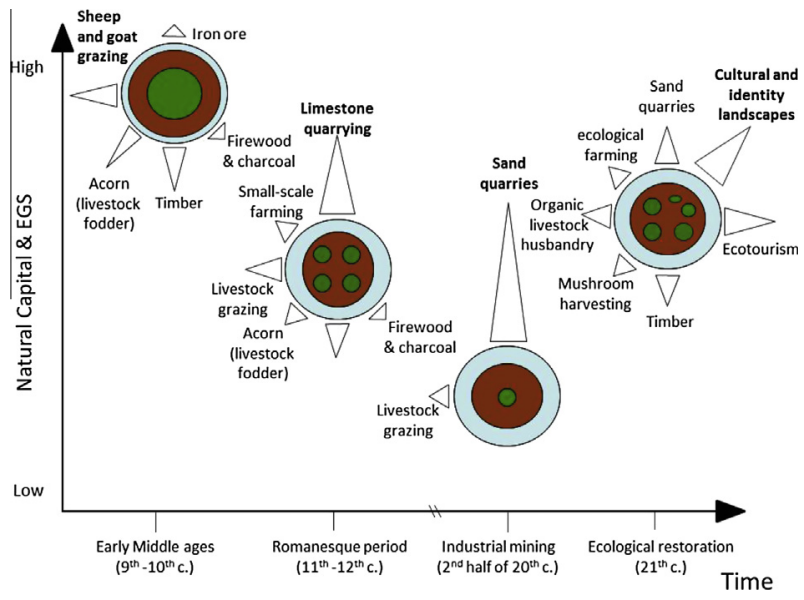

Fig. 4. Sequential references for the ecological restoration of slope sand quarries in Eastern and Central Spain over the last two millennia and as projected for the 21st century CE. Each 'star' or group of concentric circles represents an historical configuration of the ecosystem; the inner circle represents the ecosystem itself, while the two outer circles represent the landscape (biophysical matrix) and the socioeconomic matrix in which the ecosystem is embedded; the triangular appendages represent the main ecosystem goods and services (EGS) rendered by the ecosystem.

for historical continuity including, where appropriate, the human footprint. After all, ecological restoration interventions themselves are simply one more in a series of human-mediated 'disturbances', but in a new sense and spirit.

\section{Acknowledgements}

To a large extent, this paper is the outcome of collaboration among research teams within a network on ecological restoration funded by the Madrid Regional Government, Project REMEDINAL- 2, S2009/AMB-1783. The case study of the geomorphic historical reference was developed with financial support of the Spanish Research Project CGL2010-21754-C02-01, and a research contract with the mining company CAOBAR, designed to improve the effec-tiveness of ecological restoration efforts in their quarries. We thank María Tejedor who constructed the geomorphic design of the gullies, replicating existing nearby gullied landforms, and Ignacio Zap-ico, for the geomorphic design of slope piedmont. JA thanks Andre Clewell and Edouard Le Floc'h for stimulating discussions and col-laboration over many years. We also thank warmly two anony-mous reviewers for their thoughtful and very helpful comments on a previous version of the manuscript.

\section{Appendix A. Supplementary material}

Supplementary data associated with this article can be found, in the online version, at http://dx.doi.org/10.1016/j.biocon.2014. 05.007. These data include Google maps of the most important areas described in this article.

\section{References}

Aronson, J., Alexander, S., 2013a. Ecosystem restoration is now a global priority: time to roll up our sleeves. Restor. Ecol. 21, 293-296.

Aronson, J., Alexander, S., 2013b. Steering towards Sustainability requires taking ecological restoration on board. Natureza \& Conservação 11 (2), 1-11. Aronson, J.,

Floret, C., Le Floc'h, E., Ovalle, C., Pontanier, R., 1993. Restoration and rehabilitation of degraded ecosystems. I. A view from the South. Restor. Ecol. 1, $8-17$.

Aronson, J., Dhillion, S., Le Floc'h, E., 1995. On the need to select an ecosystem of reference, however imperfect: a reply to Pickett and Parker. Restor. Ecol. 3, 1-3.

Aronson, J., Van Andel, J., 2012. Restoration ecology and the path to sustainability. In: Van Andel, J., Aronson, J. (Eds.), Restor. Ecol.: New Front.. Wiley-Blackwell, Oxford, UK, pp. 293-304.
Aronson, J., Claeys, F., Westerberg, V., Picon, P., Bernard, G., Bocognano, J.M., de Groot, R., 2012. Steps towards sustainability and tools for restoring natural capital: Etang de Berre (southern France) case study. In: Weinstein, M., Turner, E. (Eds.), Sustainability Science: Balancing Ecology and Economy. Springer, New York, pp. 111138.

Bain, D.J., Smith, S.M.C., Nagle, G.N., 2008. Reservations about dam findings. Science 321, 910-912.

Balaguer, L., Arroyo-García, R., Jiménez, P., Jiménez, M.D., Villegas, L., Cordero, I., Rubio de Casas, R., Fernández-Delgado, R., Ron, M.E., Manrique, E., Vargas, P., Cano, E., Pueyo, J.J., Aronson, J., 2011. Forest restoration in a fog oasis: evidence indicates need for cultural awareness in constructing the reference. PLoS ONE 6, e23004.

Balée, W., 2010. Diversity on anthropic landscapes. Diversity 2, 163-181. Bañares, Á., BlancaG., Güemes, J., Moreno, J.C., Ortiz, S., 2010. Atlas y libro rojo de la flora vascular amenazada de España. Adenda 2010. Dirección General de Medio Natural y Política Forestal (Ministerio de Medio Ambiente, y Medio Rural y Marino)-Sociedad Española de Biología de la Conservación de Plantas, Madrid.

Barbier, E., Moreno-Mateos, D., Rogers, A., Aronson, J., Pendleton, L., Van Dover, C., Donavaro, R., Harvey, L.-A., Morato, T., Ardron, J., 2014. Protect the deep-sea. Nature 505, 476-477.

Barthel, S., Folke, C., Colding, J., 2010. Social-ecological memory in urban gardensretaining the capacity for management of ecosystem services. Global Environ. Change. 20, 255-265.

Bengtsson, J., Angelstam, P., Elmqvist, T., Emanuelsson, U., Folke, C., Ihse, M., Moberg, F., Nyström, M., 2003. Reserves, resilience and dynamic landscapes. Ambio 32, 389-396.

Blanco, E., Casado, M.A., Costa-Tenorio, M., Escribano-Bombín, R., García-Antón, M., Génova, M., Gómez-Manzaneque, A., Gómez-Manzaneque, F., Moreno, J.C., Morla, C., Regato, P., Saínz-Ollero, H., 2001. Los Bosques Ibéricos: Una Interpretación Geobotánica. Planeta, Barcelona.

Blondel, J., Aronson, J., Bodiou, J.-Y., Boeuf, G., 2010. The Mediterranean Region: Biological Diversity in Space and Time, second ed. Oxford University Press, Oxford, UK.

Bradshaw, A.D., 1996. Underlying principles of restoration. Can. J. Fish. Aquat. Sci. $53,3-9$.

Bull, J.W., Gordon, A., Law, E.A., Suttle, K.B., Milner-Gulland, J., 2014. Importance of baseline specification in evaluating conservation interventions and achieving no net loss of Biodiversity. Conserv. Biol. in press. http://dx.doi.org/10.1111/cobi.12243.

Bush, M.B., Silman, M.R., 2007. Amazonian exploitation revisited: ecological asymmetry and the policy pendulum. Front. Ecol. Environ. 5, 457-465. Butzer, K.W.,

2008. Challenges for a cross-disciplinary geoarchaeology: the intersection between environmental history and geomorphology. Geomorphology 101, 402-411.

Carrión, J.S., Fernández, S., González-Sampériz, P., Gil-Romera, G., Badal, E., CarriónMarco, Y., López-Merino, L., López-Sáez, J.A., Fierro, E., Burjachs, F., 2010. Expected trends and surprises in the Lateglacial and Holocene vegetation history of the Iberian Peninsula and Balearic Islands. Rev. Palaeobot. Palyno. 162, 458-475.

CBD (Convention on Biological Diversity), 2012. COP 11 Decision X1/16. Ecosystem Restoration <http://www.cbd.int/decision/cop/default.shtml?id=13177> (accessed 04.12.13).

Clements, F.E., Sherford, V.E., 1939. Bioecology. John Wiley \& Sons, New York, USA

Clewell, A., 2009. Guidelines for reference model preparation. Ecol. Rest. 27, 244246.

Clewell, A.F., Aronson, J., 2013a. Ecological Restoration: Principles, Values, and Structure of an Emerging Profession, second ed. Island Press, Washington, DC. Clewell,

A.F., Aronson, J., 2013b. The SER primer and climate change. Ecol. Manage. Rest. 14, 182-186.

Collins, B.D., Montgomery, D.R., Fetherston, K.L., Abbe, T.B., 2012. The floodplain large-wood cycle hypothesis: a mechanism for the physical and biotic structuring of temperate forested alluvial valleys in the North Pacific coastal ecoregion. Geomorphology $139-140,460-470$.

Crosby, A.W., 2004. Ecological imperialism: The biological expansion of Europe, 900-1900. Cambridge University Press, Cambridge, UK.

Devoto, M., Bailey, S., Craze, P., Memmot, J., 2012. Understanding and planning ecological restoration of plant-pollinator networks. Ecol. Lett. 15, 319328.

Egan, D., Howell, E.A., 2001. The Historical Ecology Handbook: A Restorationist's Guide to Reference Ecosystems. Island Press, Washington, DC

Ellis, E.C., Kaplan, J.O., Fuller, D.Q., Vavrus, S., Goldewijk, K.K., Verburg, P.H., 2013.Used Planet: A Global History. PNAS, doi: http://dx.doi.org/10.1073/ pnas. 1217241110.

Falk, D., 1990. Discovering the future, creating the past: some reflections on restoration. Ecol. Rest. 8, 71-72.

FAO, 2010. Global Forest Resources Assessment 2010: Main Report. Food and Agriculture Organization of the United Nations, Rome.

Faulkner, W., 1951. Requiem for a Nun. Random House, New York.

Ford, A., Nigh, R., 2009. Origins of the Maya forest garden: Maya resource management. J. Ethnobiol. 29, 213-236.

Franklin, J.F., MacMahon, J.A., Swanson, F.J., Sedell, J.R., 1985. Ecosystem responses to the eruption of Mount St. Helens. Natl. Geogr. Res. 1, 198-216.

Freeman, L.G., 1973. The significance of mammalian faunas from Paleolithic occupations in Cantabrian Spain. Am. Antiquity 38, 3-44.

Freinkel, S., 2007. American Chestnut: The Life, Death, and Rebirth of a Perfect Tree. University of California Press, Berkeley, CA. 
Fukami, T., Bezemer, T.M., Mortimer, S.R., van der Putten, W.H., 2005. Species divergence and trait convergence in experimental plant community assembly. Ecol. Lett. 8, 1283-1290

Ginzberg, E., 1942. A World without Work. Transaction Publishers, New Brunswick, NJ.

Hall, M., 2005. Earth Repair: A Transatlantic History of Environmental Restoration. University of Virginia Press, Charlottesville, VA.

Hancock, G.R., Loch, R.J., Willgoose, G.R., 2003. The design of post-mining landscapes using geomorphic principles. Earth Surf. Proc. Land. 28, 1097-1110. Harvey,

C., Komar, O., Chazdon, R., Ferguson, B., Finegan, B., Griffith, D., MartinezRamos, M., Morales, H., Nigh, R., Soto-Pinto, L., 2008. Integrating agricultural landscapes with biodiversity conservation in the Mesoamerican hotspot. Conserv. Biol. 22, 8-15.

Haws, J.A., 2012. Paleolithic socionatural relationships during MIS 3 and 2 in central Portugal. Quatern. Int. 264, 61-77.

Herrera, C.M., 1992. Historical effects and sorting processes as explanations for contemporary ecological patterns: character syndromes in Mediterranean woody plants. Am. Nat. 140, 421-446.

Hobbs, R.J., Arico, S., Aronson, J., Baron, J.S., Bridgewater, P., Cramer, V.A., Epstein, P.R., Ewel, J.J., Klink, C.A., Lugo, A.E., Norton, D., Ojima, D., Richardson, D.M., Sanderson, E.W., Valladares, F., Vilà, M., Zamora, R., Zobel, M., 2006. Novel ecosystems: theoretical and management aspects of the new ecological world order Global Ecol. Biogeogr. 15, 1-7.

Hobbs, R.J., Higgs, E., Harris, J.A., 2009. Novel ecosystems: implications for conservation and restoration. Trends Ecol. Evol. 24, 599-605.

Hooke, R.L., Martín-Duque, J.F., Pedraza, J., 2012. Land transformation by humans. GSA Today $22,4-10$

Iriondo, J.M., Albert, M.J., Giménez Benavides, L., Domínguez Lozano, F., Escudero, A., 2009. Poblaciones en peligro: Viabilidad demográfica de la flora vascular amenazada de España. Dirección General de Medio Natural y Política Forestal (Ministerio de Medio Ambiente, y Medio Rural y Marino), Madrid.

Jackson, S.T., Hobbs, R.J., 2009. Ecological restoration in the light of ecological history. Science $325,567-569$.

Larkin, D., Vivian-Smith, G., Zedler, J.B., 2006. Topographic heterogeneity theory and ecological restoration. In: Falk, D., Palmer, M., Zedler, J. (Eds.), Foundations of Restoration Ecology. Island Press, Washington, DC, pp. 142-164.

Lucía, A., Laronne, J.B., Martín-Duque, J.F., 2011. Geodynamic processes on sandy slope gullies in Central Spain. Field observations, methods and measurements in a singular system. Geodin. Acta 24, 61-79.

Lundberg, J., Moberg, F., 2003. Mobile link organisms and ecosystem functioning: implications for ecosystem resilience and management. Ecosystems 6, 87-98. Manning,

A.D., Gibbons, P., Lindenmayer, D.B., 2009. Scattered trees: a complementary strategy for facilitating adaptive responses to climate change in modified landscapes? J. Appl. Ecol. 46, 915-919.

Martín-Duque, J.F., Sanz, M.A., Bodoque, J.M., Lucía, A., Martín-Moreno, C., 2010. Restoring earth surface processes through landform design. A 13-year monitoring of a geomorphic reclamation model for quarries on slopes. Earth Surf. Proc. Land. 35, 531-548.

Mascaro, J., Becklund, K.K., Hughes, R.F., Schnitzer, S.A., 2008. Limited native plant regeneration in novel, exotic-dominated forests on Hawai'i. Forest Ecol. Manage. 256, 593-606.

McCune, J.L., Pellatt, M.G., Vellend, M., 2013. Multidisciplinary synthesis of longterm human-ecosysteminteractions: a perspective from the Garry oak ecosystem of British Columbia. Biol. Conserv. 166, 293-300.

Millar, C, Stephenson, N.L., Stephens, S.L. 2007. Climate change and forests of the future: managing in the face of uncertainty. Ecol. Appl. 17, 2145-2151. Miller, S.J.,

Pruitt, B.A., Theiling, C.H., Fischenich, J.C., Komlos, S.B., 2012. Reference Concepts in Ecosystem Restoration and Environmental Benefits Analysis (EBA): Principles and Practices.EMRRP-EBA-12, U.S. Army Engineer Research and Development Center, Vicksburg, MS, USA.

Ministerio de Medio Ambiente, 1999. Estrategia forestal española. Ministerio de Medio Ambiente, Madrid.

Mola, I., Jiménez, M.D., López-Jiménez, N., Casado, M.A., Balaguer, L., 2011. Roadside reclamation outside the revegetation season: management options under schedule pressure. Rest. Ecol. 19, 83-92.

Moreno-Mateos, D., Power, M.E., Comin, F.A., Yockteng, R., 2012. Structural and functional loss of restored wetland ecosystems. PLoS Biol. 10, e1001247.

Murcia, C., Aronson, J., 2014. Intelligent tinkering in ecological restoration. Rest. Ecol. 22 (4), 279-283.

Naveh, Z., 2000. The total human ecosystem: integrating ecology and economics. Bioscience 50, 357
Nigh, R., Diemont, A.W., 2013. The Maya milpa: fire and the legacy of living soil. Front. Ecol. Environ. 11, e45-e54.

Olano, J.M., Caballero, I., Escudero, A., 2011. Soil seed bank recovery occurs more rapidly than expected in semi-arid Mediterranean gypsum vegetation. Ann. Bot. 109, 299-307.

Olsson, P., Folke, C., Berkes, F., 2004. Adaptive co-management for building resilience in social-ecological systems. Environ. Manage. 34, 75-90.

Owen-Smith, N., 1987. Pleistocene extinctions: the pivotal role of megaherbivores. Paleobiology 13, 351-362.

Pauly, D., 1995. Anecdotes and the shifting baseline syndrome of fisheries. Trends Ecol. Evol. 10, 430.

Peterson, G.D., 2002. Contagious disturbance, ecological memory, and the emergence of landscape pattern. Ecosystems 5, 329-338.

Pickett, S.T.A., Parker, V.T., 1994. Avoiding the old pitfalls: opportunities in a new discipline. Rest. Ecol. 2, 75-79.

Pickett, S.T.A., White, P.S., 1985. The Ecology of Natural Disturbance and Patch Dynamics. Academic Press, San Diego, CA, USA.

Ramirez-Llodra, E., Tyler, P.A., Baker, M.C., Bergstad, O.A., Clark, M.R., Escobar, E., Levin, L.A., Menot, L., Rowden, A.A., Smith, C.R., Van Dover, C.L., 2011. Man and the last great wilderness: human impact on the deep sea. PLoS ONE 6, e22588. Rathus,

S.A., 2000. Essentials of Psychology. Harcourt Brace College Publishers, Fort Worth, TX.

Rey Benayas, J.M., Bullock, J.M., Newton, A.C., 2008. Creating woodland islets to reconcile ecological restoration, conservation, and agricultural land use. Front. Ecol. Environ. 6, 329-336.

Schaefer, V., 2009. Alien invasions, ecological restoration in cities and the loss of ecological memory. Rest. Ecol. 17, 171-176.

SECF (Sociedad Española de Ciencias Forestales), 2011. Situación de los Bosques y del Sector Forestal en España. Informe 2010. <http://es.scribd.com/doc/ 101155481/infores2010> (accessed 04.12.13)

SER (Society for Ecological Restoration International Science \& Policy Working Group), 2004. The SER International Primer on Ecological Restoration. Society for Ecological Restoration International, Tucson, AZ.

Shoo, L.P., Catterall, C.P., 2013. Stimulating natural regeneration of tropical forest on degraded land: approaches, outcomes, and information gaps. Rest. Ecol. 21, 670-677.

Simberloff, D., Vitule, J.R.S., 2014. A call for an end to calls for the end of invasion biology. Oikos 123, 408-413.

Tansley, A.G., 1935. The use and abuse of vegetational concepts and terms. Ecology 16,284

Tarsaidze, A., 1950. American pioneers in Russian railroad building. Russ. Rev. 9, 286-295.

Temperton, V.M., Hobbs, R.J., Nuttle, T., Halle, S. (Eds.), 2004. Assembly Rules and Restoration Ecology. Island Press, Washington, D.C..

Thompson, J.N., Reichman, O.J., Morin, P.J., Polis, G.A., Power, M.E., Sterner, R.W., Couch, C.A., Gough, L., Holt, R., Hooper, D.U., Keesing, F., Lovell, C.R., Milne, B.T., Molles, M.C., Roberts, D.W., Strauss, S.Y., 2001. Frontiers of ecology. Bioscience 51, $15-24$.

Van Dover, C.L., Aronson, J., Pendleton, L., et al., 2013. Ecological restoration in the deep sea: desiderata. Mar. Policy. http://dx.doi.org/10.1016/j.marpol.2013.07.006.

Von Holle, B., Delcourt, H.R., Simberloff, D., 2003. The importance of biological inertia in plant community resistance to invasion. J. Veg. Sci. 14, 425432.

Walter, R.C., Merritts, D.J., 2008. Natural streams and the legacy of water-powered mills. Science 308, 299-304.

Waltner-Toews, D., Kay, J.J., Neudoerffer, C., Gitau, T., 2003. Perspective changes everything: managing ecosystems from the inside out. Front. Ecol. Environ. 1, $23-30$.

White, P.S., Walker, J.L., 1997. Approximating nature's variation: selecting and using reference information in restoration ecology. Rest. Ecol. 5, 338-349.

Wilson, E.O., 1984. Biophilia. Harvard University Press, Cambridge, MA.

Wilson, E.O., 1992. The diversity of life. The Penguin Press, London.

Woodworth, P., 2013. Restoring the earth. Chicago University Press, Chicago, IL. Wu, J.,

2010. Landscape of culture and culture of landscape: does landscape ecology need culture? Landscape Ecol. 25, 1147-1150.

$\mathrm{Wu}, \mathrm{J} ., 2$ 2011. Integrating nature and culture in landscape ecology. In: Hong, S.-K., Kim, J.-E., Wu, J., Nakagoshi, N. (Eds.), Landscape Ecology in Asian Cultures. Springer, Tokyo, Japan.

Young, T.P., Petersen, T.A., Clary, J.J., 2005. The ecology of restoration: historical links, emerging issues and unexplored realms. Ecol. Lett. 8, 662-673. 